\title{
Nanoparticles Targeting Hepatic Stellate Cells for the Treatment of Liver Fibrosis
}

\author{
Qiaobin Hu, Ji-Young Lee and Yangchao Luo*
}

Liver fibrosis is a scarring process that can progress to cirrhosis, the primary cause for hepatocellular carcinoma. Although various anti-fibrotic agents have been explored for liver fibrosis treatment, their clinical applications have been limited due to insufficient delivery of the agents to target cells and toxicity. Hepatic stellate cells (HSC) play key roles in the development of liver fibrosis because they produce extracellular matrix proteins, such as collagens, when activated upon liver injury. Therefore, surface engineering of organic nanoparticles (such as liposomes, polymeric, and lipid nanoparticles) with ligands specific to the overexpressed receptors secreted by activated HSC during hepatic fibrogenesis has been exploited in the last decade to develop effective approaches to reverse liver fibrosis. Passive targeting has also been explored as a potential strategy to deliver anti-fibrotic agents to activated HSC through systemic administration of non-ligand nanoparticles, including both organic (polymeric and lipid) and inorganic (mesoporous silica, cerium oxide and silver) nanoparticles. This review focuses on the most recent literatures concerning different types of nanoparticles for liver fibrosis treatment via HSC-targeting delivery of various anti-fibrotic agents by the two strategies aforementioned, with special emphasis on their therapeutic mechanisms and biological efficacies at both cellular and the whole body levels.

Keywords: Nanoparticles; Liver fibrosis; Hepatic stellate cells; Ligands; Targeting delivery

Received 3 March 2019, Accepted 15 March 2019

DOI: $10.30919 / \mathrm{es} 8 \mathrm{~d} 507$

\section{Introduction}

The liver is the largest internal organ in mammals, serving a wide spectrum of crucial functions, such as detoxification, protein and lipid synthesis, bile acid production, glycogen storage, as well as metabolic homeostasis of macronutrients. ' Unfortunately, chronic liver diseases have been a global health problem with limited treatment options available. Various factors damage the liver, including chronic hepatitis $\mathrm{B}$ and hepatitis $\mathrm{C}$ virus infections, alcohol abuse, genetic abnormalities, steatohepatitis, obesity and autoimmunity. ${ }^{2}$ Without proper treatment, chronic damage to the liver induces liver fibrosis, which manifests excessive deposition of extracellular matrix (ECM) and fibrous connective tissue.,

The liver contains several cell types, including hepatocytes, endothelial cells, Kupffer cells, hepatic stellate cells (HSC), and intrahepatic lymphocytes. ${ }^{5}$ In particular, it is known that the activation of quiescent HSC to ECM-producing myofibroblasts, i.e., activated HSC (Fig. 1), is a central event in response to an insult of chronic liver injury. ${ }^{6,7}$ In the healthy liver, the main functions of quiescent HSC are vitamin A storage and maintenance of $\mathrm{ECM}^{8}$. Once activated during liver injury, HSC produce cytokines, such as platelet-derived growth factor (PDGF) and transforming growth factor $\beta$ (TGF- $\beta$ ), facilitating the differentiation and proliferation of HSC. ${ }^{9}$ Activated HSC are highly

Department of Nutritional Sciences, University of Connecticut, Storrs, CT 06269, USA

*E-mail: yangchao.luo@uconn.edu proliferative and produce large quantity of proteins, such as interstitial collagen (mainly type I and III), $\alpha$-smooth muscle actin ( $\alpha$-SMA), proteoglycans and matrix metalloproteinase, ${ }^{10,11}$ as well as vascular endothelial growth factor (VEGF) and PDGF that promote inflammation and angiogenesis. ${ }^{12}$ As a result, liver fibrosis progresses to cirrhosis, portal hypertension, liver failure and ultimately hepatocellular carcinoma. Although advanced liver diseases are irreversible, it has been shown that the early-stage liver fibrosis can be reversed when causes of the disease are removed.

Various anti-fibrotic molecules, including drugs, nutrients, and small interfering RNA (siRNA), have been tested for the treatment of liver fibrosis in preclinical studies. Paclitaxel, an anti-cancer drug, has been shown to inhibit the activation of HSC by targeting the TGF- $\beta$ pathway. ${ }^{14,15}$ Sorafenib, a dual-function tyrosine kinase inhibitor widely used for the treatment of liver cancer, also inhibits the proliferation of HSC while facilitating apoptosis of activated HSC by downregulating Cyclin D1 and cyclin-dependent kinase $4{ }^{16}$ Silymarin, another wellknown hepatoprotective drug, promotes ECM degradation while inactivating HSC. ${ }^{17,18}$

Natural products with a potential anti-fibrotic property have drawn attention recently due to low toxicity and costs. Curcumin, a diarylheptanoid obtained from turmeric, suppresses HSC activation by inhibiting the TGF- $\beta$ signaling and downregulating the expression of PDGF receptor. ${ }^{19}$ Astaxanthin, a xanthyophyll carotenoid from red marine animals such as salmon and shrimp, has been demonstrated to inhibit fibrogenesis in primary human and mouse HSC cell lines, ${ }^{20,21}$ as well as in a mouse model of diet-induced nonalcoholic steatohepatitis ${ }^{22}$. Other nutrient and non-nutrient bioactive compounds, such as Vitamin $\mathrm{E}^{23}$ sodium ferulate ${ }^{24}$ and epigallocatechin-3-gallate (EGCG) from green 
tea, ${ }^{25}$ also exhibit anti-fibrotic effects in animals. In addition, it has been shown that siRNAs have high efficiency and specificity for liver fibrosis. ${ }^{26,27}$ Nevertheless, various challenges to the treatment of liver fibrosis using the aforementioned agents exist. The oral administration of anti-fibrotic agents may have adverse effects due to non-specific cellular uptake, and their therapeutic efficacy may be low because of their instability during digestion and absorption. For instance, the low bioavailability, poor water solubility and instability of astaxanthin when exposed to oxygen and $\mathrm{pH}$ extremes have been reported. ${ }^{28,29}$ Intravenous therapy also has issues with local reaction, drug incompatibilities, and patient non-compliance. For instance, in vivo potency of siRNAs therapeutics, when administered through subcutaneous or intravenous injection, is often hindered by poor intracellular uptake, limited blood stability, non-specific immune stimulation, and high renal clearance. ${ }^{30}$ Therefore, to achieve better therapeutic efficacy for the treatment of liver fibrosis, there is an urgent need to develop effective targeting delivery systems that circumvent the aforementioned issues and directly deliver anti-fibrotic agents to the activated HSC. Over the last decade, there has been a strong interest in utilizing nanoparticulate delivery systems for the treatment of liver fibrosis. The present review summarizes two major strategies for designing HSC-targeting nanoparticles, i.e. active targeting via surface engineering of organic nanoparticles with HSC-specific ligands and passive targeting via systemic administration of non-ligand organic (polymeric and lipid) and inorganic (mesoporous silica, cerium oxide and silver) nanoparticles. The targeting mechanisms of these nanoparticles and their biological efficacies at cellular and the whole body levels are discussed in detail.

\section{Ligand conjugated nanoparticles for targeting activated $\mathrm{HSC}$}

Activated HSC highly express various cell surface receptors, such as retinol binding protein (RBP) receptor, ${ }^{31}$ integrin $\alpha_{v} \beta_{3}{ }_{3}$, mannose-6phosphate/insulin-like growth factor II (M6P/IGF II) receptor, ${ }^{33}$ PDGF receptor- $\beta{ }^{34}$ hyaluronic acid (HA) receptor $\mathrm{CD} 44^{35}$ and chemokine receptor type 4 (CXCR4). ${ }^{36}$ Therefore, ligands of these cell surface receptors may be used for surface engineering nanoparticles that contain anti-fibrotic agents to target HSC for the treatment of liver fibrosis. Each type of these ligand-conjugated nanoparticles will be introduced and their preparation, characterization, HSC-targeting efficiency as well as biological efficacy are discussed in detail in the following sections.

\subsection{Vitamin A-grafted nanoparticles}

HSC are the primary vitamin A-storing cells in the body. ${ }^{37}$ Therefore, coating nanoparticles with vitamin A may direct them to HSC via the interactions between vitamin $\mathrm{A}$ and $\mathrm{RBP}$ receptor. Toriyabe et al. ${ }^{38}$ developed siRNA-loaded lipid nanoparticles using SS-cleavable protonactivated lipid-like material (ssPalms) containing vitamin A with a particle size of $182 \mathrm{~nm}$ and nearly neutral zeta potential (Fig. 2A). The nanoparticles were formulated with addition of siRNA against type I collagen $\alpha-1$ (Col1a1), a major ECM substance produced by HSC, to knock down the gene expression. Once entering HSC, the nanoparticles disassemble due to the breakdown of disulfate bonds in ssPalms by intracellular glutathione (GSH), releasing Collal siRNA for gene silencing. When the vitamin A-modified nanoparticles were administered to mice with $\mathrm{CCl}_{4}$-induced liver fibrosis at a dose of 3.0 mg siRNA $/ \mathrm{kg}$, collagen production was significantly decreased compared with control mice. In another study by Sato et al., ${ }^{39}$ vitamin A-coupled liposomes (VA-lip-siRNAgp46) with a particle size of 154 $\mathrm{nm}$ were developed using a freeze-dried empty liposome method to deliver siRNA against gp46, a rat homolog of human heat shock protein 47 that plays an important role in the development of liver fibrosis. Delivery efficiency of the nanoparticles to HSC was determined in rats with dimethylnitrosamine-induced liver fibrosis by intravenously injecting VA-lip-siRNAgp46 at a dose of $0.75 \mathrm{siRNA} \mathrm{mg} / \mathrm{kg}$ for their tissue distribution. As shown in Fig. 3, the fluorescence intensity of VAlip-siRNAgp46 in the $\alpha$-SMA positive area (yellow) was significantly higher than that of control, indicating their entry into HSC. The survival time of rats administered with VA-lip-siRNAgp46 was markedly higher than that of animals subjected to control liposomes without vitamin A modification.

Pan et $a l^{40}$ also evaluated the effects of vitamin A loading and surface charge of lipid nanoparticles on HSC-targeting efficiency and biodistribution using silybin as a model drug as it is known to inhibit oxidative stress related to liver fibrosis. ${ }^{41}$ To prepare nanoparticles with different surface charge, aqueous phase either containing anionic deoxycholic acid or cationic soyaethyl morpholinium ethosulfate was added into lipid phase containing both solid (hexadecyl palmitate) and

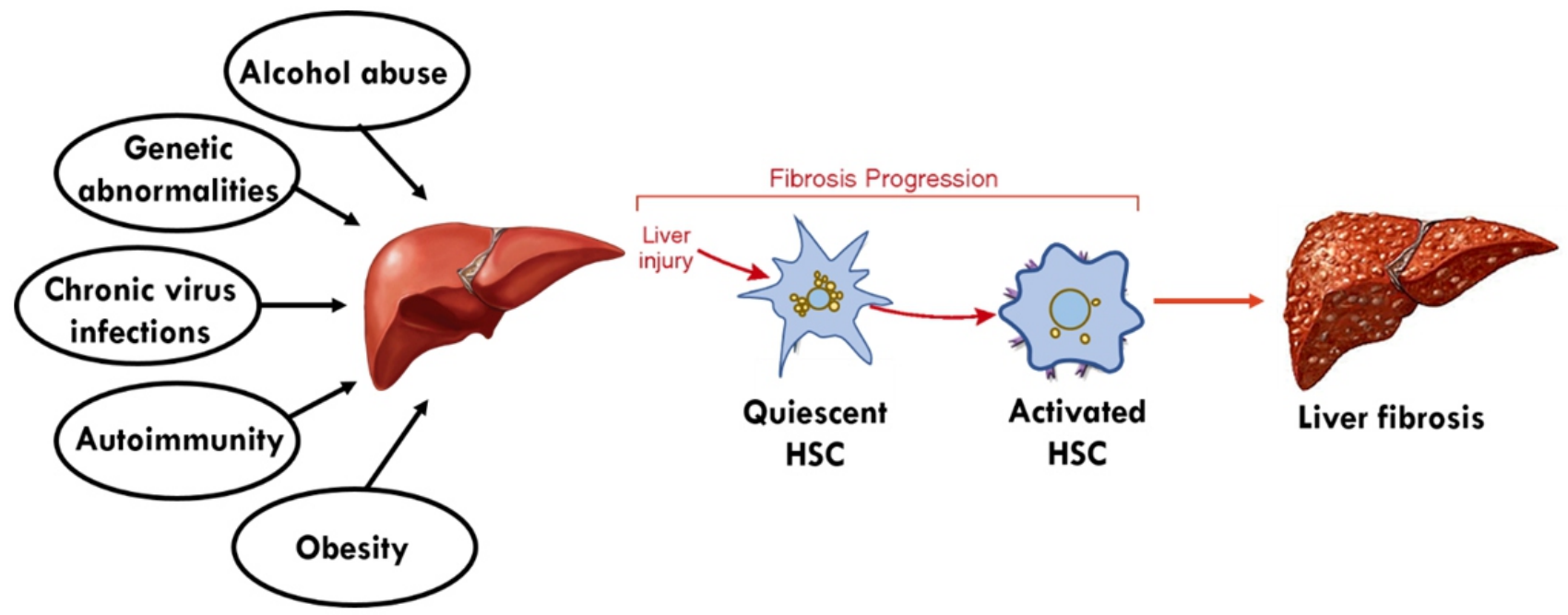

Fig. 1 Scheme of development of liver fibrosis upon activation of HSC by chronic liver injury. 


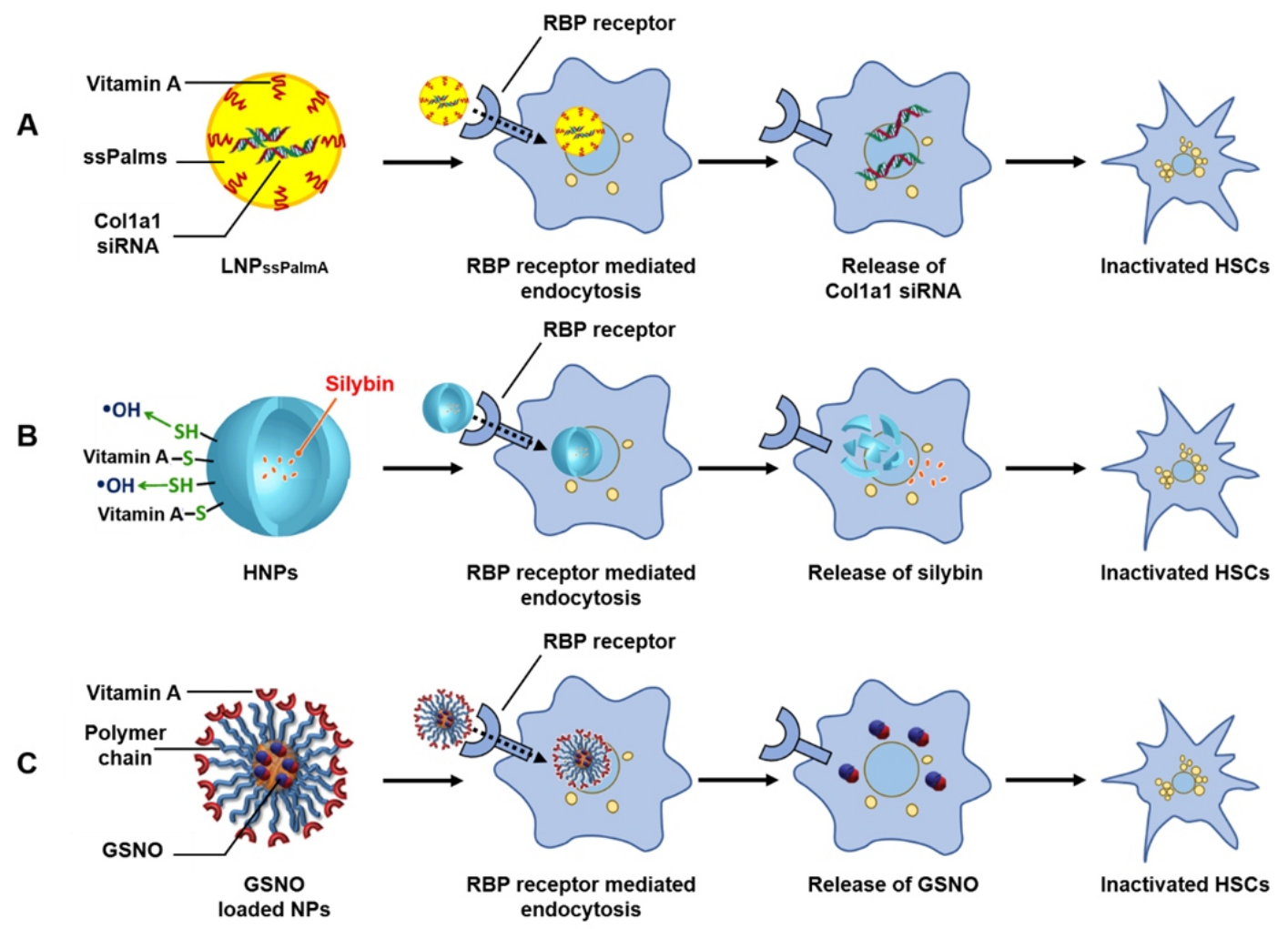

Fig. 2 The schematic illustration of ligand grafted nanoparticles for HSC targeting delivery: vitamin-A scaffold contained lipid nanoparticles (A), vitamin A grafted organic-inorganic (silica) hybrid hollow nanoparticles (B), and vitamin A decorated S-nitrosoglutathione loaded nanoparticles (C). The drawings of hepatic stellate cells are adapted from ref. "S. L. Friedman, Proceedings of National Academy of Sciences of the United States, 2012, 109, 9230-9231". Permission is not needed as specified on the publisher's website. Copyright 2012, National Academy of Sciences.

\section{VA-lip-siRNAgp46}
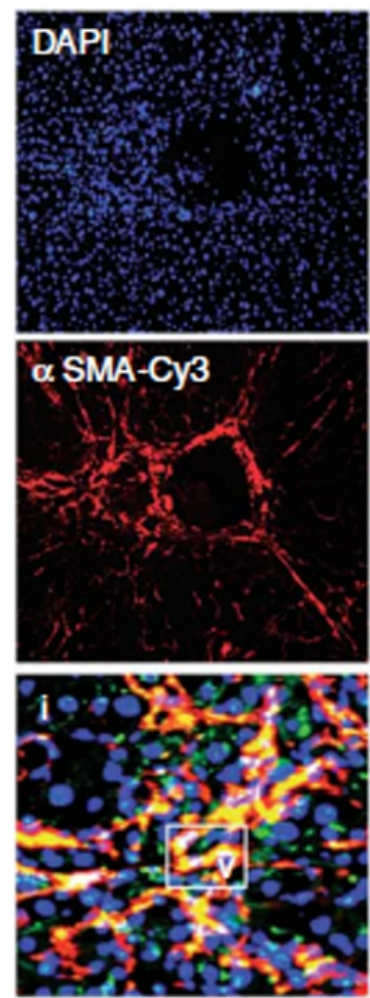
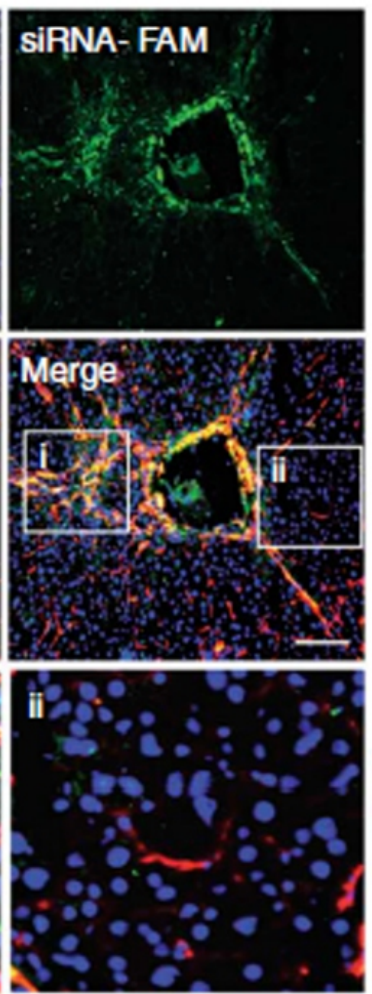

\section{Lip-siRNAgp46}
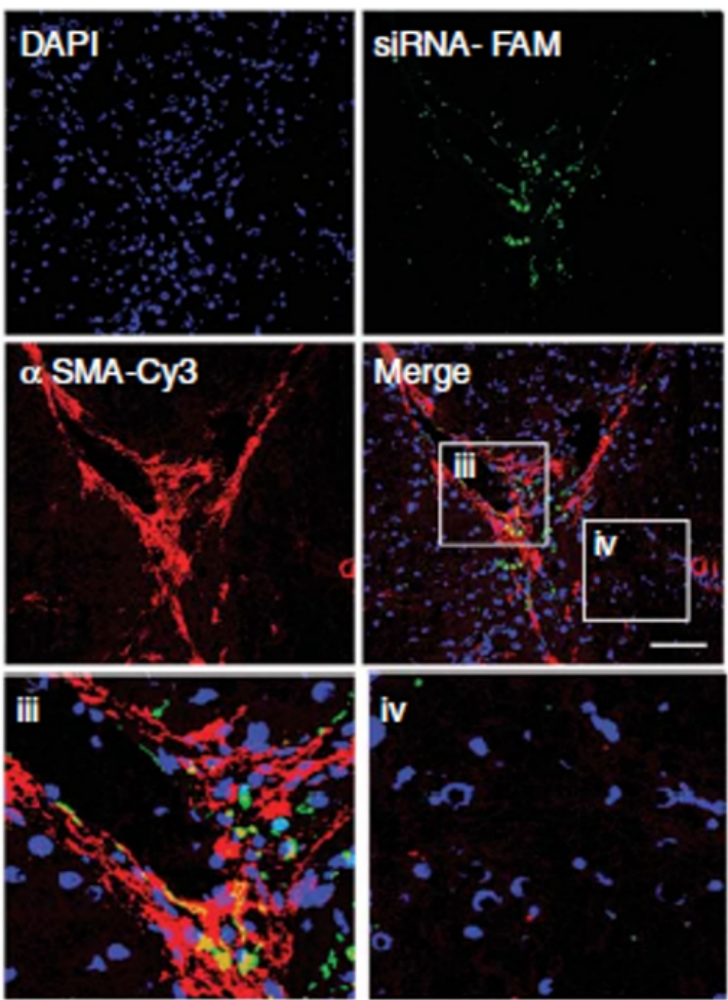

Fig. 3 Representative fluorescent images of $\alpha$-SMA visualized by Cy3-conjugated anti- $\alpha$-SMA antibody (red), nuclei counterstained with DAPI (blue) and siRNAgp46-FAM (green) in liver specimens. Pictures taken at original magnification $(\times 200)$ and magnified images corresponding to the areas enclosed in boxes are presented in i, ii and iii, iv. Reprinted with permission from ref. 39. Copyright 2008, Springer Nature. 
liquid (soybean phosphatidylcholine) lipids, as well as vitamin A. The positively charged nanoparticles showed a mean size of $\sim 260 \mathrm{~nm}$, which was greater than that of negatively charged nanoparticles (170 $\mathrm{nm}$ ). The zeta potential of two different nanoparticles were +25.1 and $33.0 \mathrm{mV}$, respectively. The solid and liquid lipid mixture showed several advantages, such as decreased silybin entrapment, sustained drug release, and enhanced drug targeting. Although it is known that lipid nanoparticles are transported into the liver due to their lipophilic nature and recognition by resident phagocytic cells, ${ }^{42}$ the presence of vitamin A in nanoparticles facilitated specific-targeting of the particles to HSC in the liver. Furthermore, a study for the in vivo biodistribution of silybin demonstrated that the hepatic silybin levels in treated with vitaminloaded lipid nanoparticles was 2-3 folds higher than that treated with the control lipid nanoparticles and free silybin. The cationic nanoparticles induced more apoptosis of activated HSC while inhibitory effects on $\alpha$ SMA was lower than those of anionic nanoparticles at a silybin dose of $0.8 \mathrm{mg} / \mathrm{kg}$, indicating that nanoparticles with a different surface charge may exert different functions in HSC. Future studies are warranted to determine how nanoparticles with different surface charge impact survival and functions of activated HSC.

In addition to lipid-based nanoparticles, other types of nanoparticles have also been explored to target HSC through surface engineering with vitamin A. Novel organic-inorganic (silica) hybrid hollow nanoparticles (HNPs) with a framework comprised of disulfide and siloxane and a surface containing thiol groups have been used for the targeted delivery of silybin to HSC, as shown in Fig. $2 \mathrm{~B}^{43}$ Vitamin A was conjugated on the surface of the nanoparticles by the interaction of vitamin A with p-maleimidophenyl isocyanate and thiol groups. The vitamin A-HNPs were specifically delivered to HSC via RBP receptorligand mediated endocytosis in mice (Fig. 4A). As shown in Fig. 4B, the disulfides in HNP framework are cleaved into thiols by intracellular glutathione, resulting in the collapse of HNPs and subsequent release of silybin within cells. Furthermore, intravenous injection of vitamin AHNPs facilitated tissue repair and improved hepatic functions in mice with $\mathrm{CCl}_{4}$-induced liver fibrosis. In another study, polymeric nanoparticles decorated with vitamin A were synthesized. ${ }^{44}$ The carboxylic acid end-groups of (4-cyanopentanoic acid)-4-dithiobenzoate (as a chain transfer agent) were exploited to conjugate vitamin A to oligoethyelene glycol-methacrylate based polymeric nanoparticles via a simple esterification in dimethyl sulfoxide (Fig. 2C). ${ }^{44}$ The vitamin Adecorated polymeric nanoparticles were ultra-small with a size of only $35 \mathrm{~nm}$, and this was the first report to demonstrate polymeric nanoparticles as an efficient nanocarrier for specific uptake by HSC via RBP receptor. Nitric oxide (NO) has been reported to inhibit the proliferation of HSC while promoting apoptosis of activated HSC. ${ }^{45}, 46$ Therefore, S-nitrosoglutathione (GSNO), a well-documented NO donor, ${ }^{47}$ was encapsulated in nanoparticles to increase cellular $\mathrm{NO}$ levels. When activated human HSC and primary rat HSC were incubated with GSNO-loaded vitamin A-nanoparticles at a GSNO dosage of $5 \times 10^{4} \mathrm{M}$, the expression of fibrogenic genes, including collagen I and $\alpha$-SMA, was decreased.

\subsection{Cyclic peptides-grafted nanoparticles}

An alternative approach for HSC-targeting delivery has been developed by grafting cyclic peptides specific for cell surface receptors in HSC onto nanoparticles via surface engineering. Amino acid sequence C*SRNLIDC* (pPB), a cyclic oligopeptide, has a strong binding affinity to PDGF receptor- $\beta .^{48,49} \mathrm{Jia}$ et al. ${ }^{27}$ prepared oligopeptide pPBmodified stable nucleic acid lipid nanoparticles (pPB-SNALP) with a particle size of $110-130 \mathrm{~nm}$ and neutral surface charge to deliver collagen-specific chaperone molecule (gp46) siRNA. Specifically, a peptide grafted phospholipid polymer conjugate was prepared by
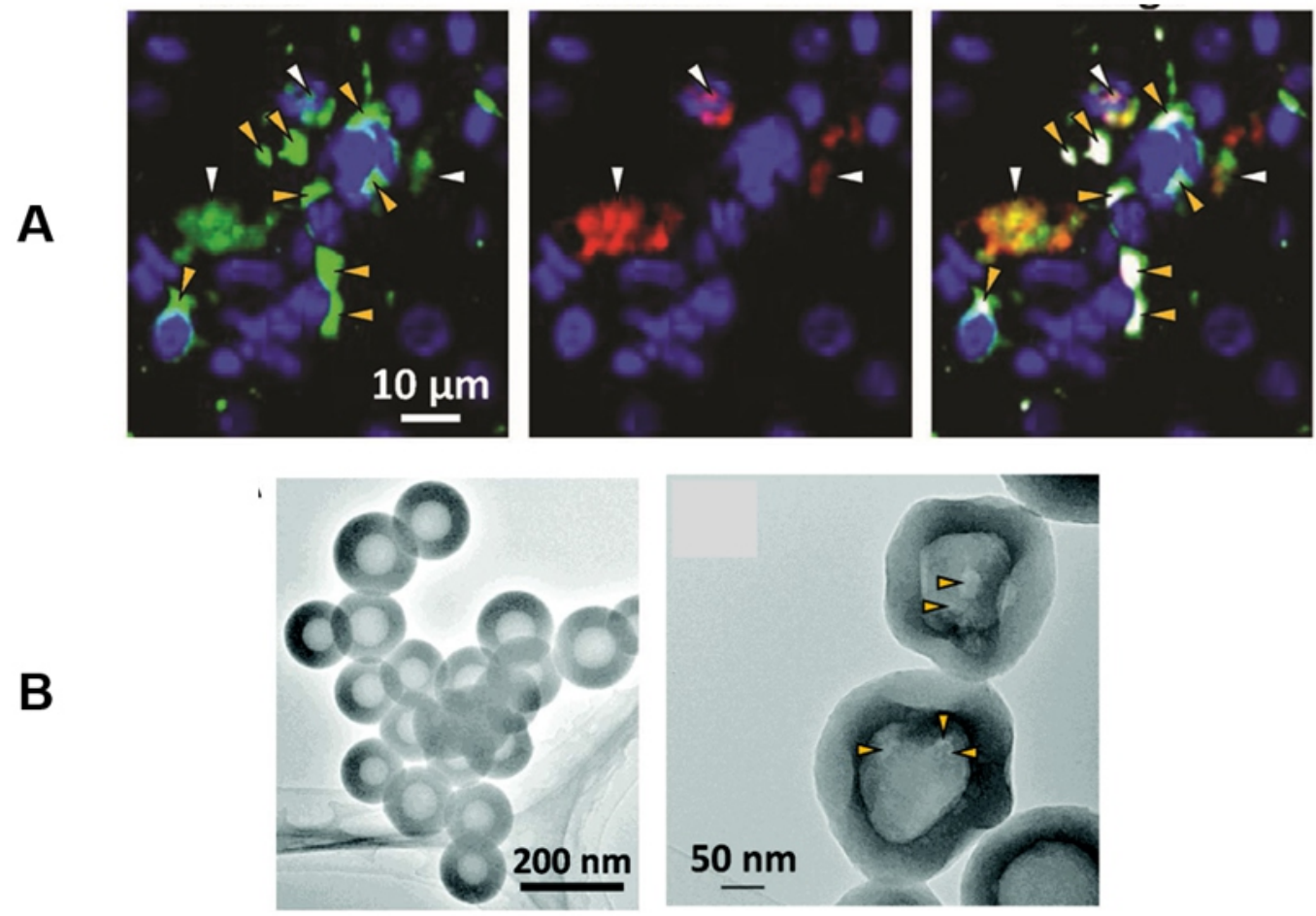

Fig. 4 Immunohistological findings of liver tissues excised from mice $24 \mathrm{~h}$ after injection of SIL-R-HNPs: nuclei counterstained with DAPI (blue), HNPs containing fluorescein isothiocyanate (green), HSC stained with tetramethylrhodamine conjugated anti-desmin antibodies (red) (A); TEM image of HNPs (left) and SIL-R-HNPs simulated with GSH (right) (B). Reprinted with permission from ref. 43. Copyright 2018, John Wiley and Sons. 
covalently bonding $\mathrm{pPB}$ to the maleimide group of 1,2-distearoyl-snglycero-3-phosphoethanolamine-poly (ethylene glycol) (PEG-DSPE). PEG is a widely used polymer in delivery systems to reduce or prevent plasma protein binding, and also it serves as a spacer for a linkage of $\mathrm{pPB}^{50}$ The gp46 siRNA was incorporated into lipids, followed by coating with pPB-PEG-DSPE (Fig. 5A). Compared with unmodified nanoparticles, pPB-containing nanoparticles showed higher cellular uptake by LX-2 cells and primary mouse HSC, as well as increased accumulation in the liver, ${ }^{27}$ as shown in Fig. 6. Furthermore, gp46 expression was markedly decreased in the fibrotic liver of mice after intravenous injection of the pPB-containing nanoparticles at a siRNA dose of $0.023 \mathrm{mg} / \mathrm{kg}$.

Integrin $\alpha_{v} \beta_{3}$, another cell surface receptor that is highly expressed in activated HSC, is able to recognize cyclic peptide ligands. Xuan et $a l .^{51}$ prepared core-shell nanoparticles by utilizing perfluorooctyl bromide (PFOB) liquid as a core, which was stabilized by poly (lacticco-glycolic acid) (PLGA) polymer shell, followed by a modification using cyclic arginine-glycine-aspartic acid (cRGD) octapeptide (Fig. 5B). The promising targeting efficiency of these nanoparticles to the activated HSC was confirmed in vitro using rat HSC-T6 cells. More importantly, the nanoparticles detect integrin $\alpha_{v} \beta_{3}$ on activated HSC at different stages of liver fibrosis, thus they generate high ultrasound images that can distinguish liver fibrosis at different stages. Therefore, the authors claimed that the as-prepared nanoparticles have very important clinical applications by offering a novel and non-invasive approach for early detection and continuous monitoring of liver fibrosis progression in patients with chronic liver diseases.

Studies have shown that collagen VI, which is abundantly produced by activated HSC, is another target for the treatment of liver fibrosis. Du et al..$^{52}$ prepared sterically stable liposomes composed of egg phosphatidylcholine, PEG conjugate and cholesterol to encapsulate interferon (IFN)- $\alpha 1 b$ using cyclic (Arg-Gly-Asp) RGD peptide as a ligand for collagen VI. IFN- $\alpha 1 b$ is known as an anti-fibrotic agent that reduces the production of collagen I and III in the liver, but it has several adverse effects such as anemia and flu-like syndromes. ${ }^{53}$ When IFN- $\alpha 1$-encapsulated liposomes were injected to mice with bile duct ligation (BDL) for the induction of liver fibrosis, at a dose of $5 \times 10^{4}$ $\mathrm{U} /$ mouse, a significant decrease in the severity of liver fibrosis was observed compared to non-ligand liposomes. Also, the sterically stabilized liposomes modified with cyclic RGD peptides have been developed to deliver hepatocyte growth factor (HGF) to activated $\mathrm{HSC}^{54}$ as HGF is known to reverse fibrogenic process by inhibiting ECM production while inducing apoptosis of myofibroblasts. ${ }^{55,56}$ The liposomes with an average particle size of $91.5 \mathrm{~nm}$ and HGF loading efficiency of $32.4 \%$ significantly reduced liver fibrosis as evidenced by diminished expression of collagen I and III, indicating that they are likely to target activated HSC.

In addition, IGF II receptor can be utilized for HSC-specific drug delivery. A peptide-modified siRNA nanocomplex was prepared by mixing biotin conjugated IGF II receptor-specific peptide and neutravidin, followed by condensation with protamine. ${ }^{26}$ The siRNA against poly (rC) binding protein 2 ( $\mathrm{PCBP} 2$ ) was encapsulated into the nanoparticles through the interaction with neutravidin to inhibit the expression of $\alpha \mathrm{CP} 2$, which is responsible for stabilization of the collagen $\alpha 1$ (I) mRNA..$^{57}$ The study demonstrated that when PCBP2 siRNA was delivered in the nanoparticles with IGF II receptor-specific peptide, it exhibited higher targeting efficacy to LX-2 (a human HSC cell line), rat HSC-T6 cell line, and activated primary rat HSC than free

A

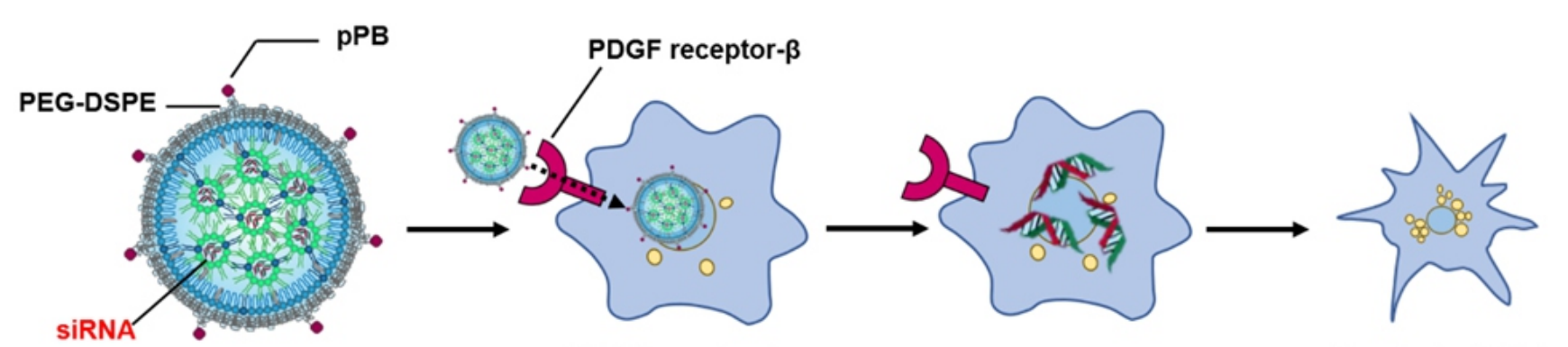

pPB-SNALP

PDGF receptor- $\beta$ mediated endocytosis

gp46 gene silencing

Inactivated HSCs

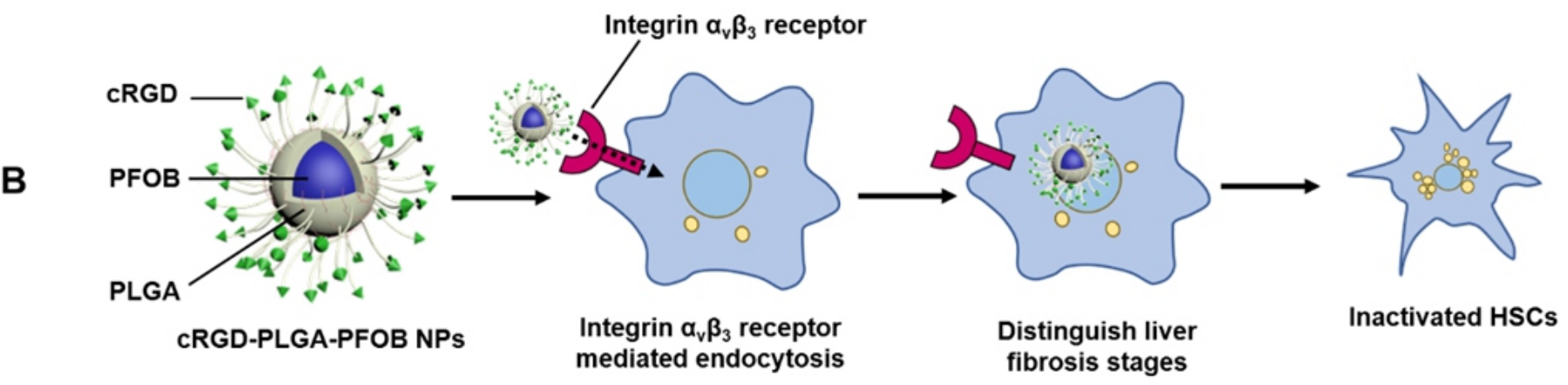

Fig. 5 The schematic illustration of ligand grafted nanoparticles for HSC targeting delivery: pPB coated nanoparticles (A), and cRGD coated PLGAPFOB nanoparticles (B). The drawings of hepatic stellate cells are adapted from ref. "S. L. Friedman, Proceedings of National Academy of Sciences of the United States, 2012, 109, 9230-9231". Permission is not needed as specified on the publisher's website. Copyright 2012, National Academy of Sciences. 


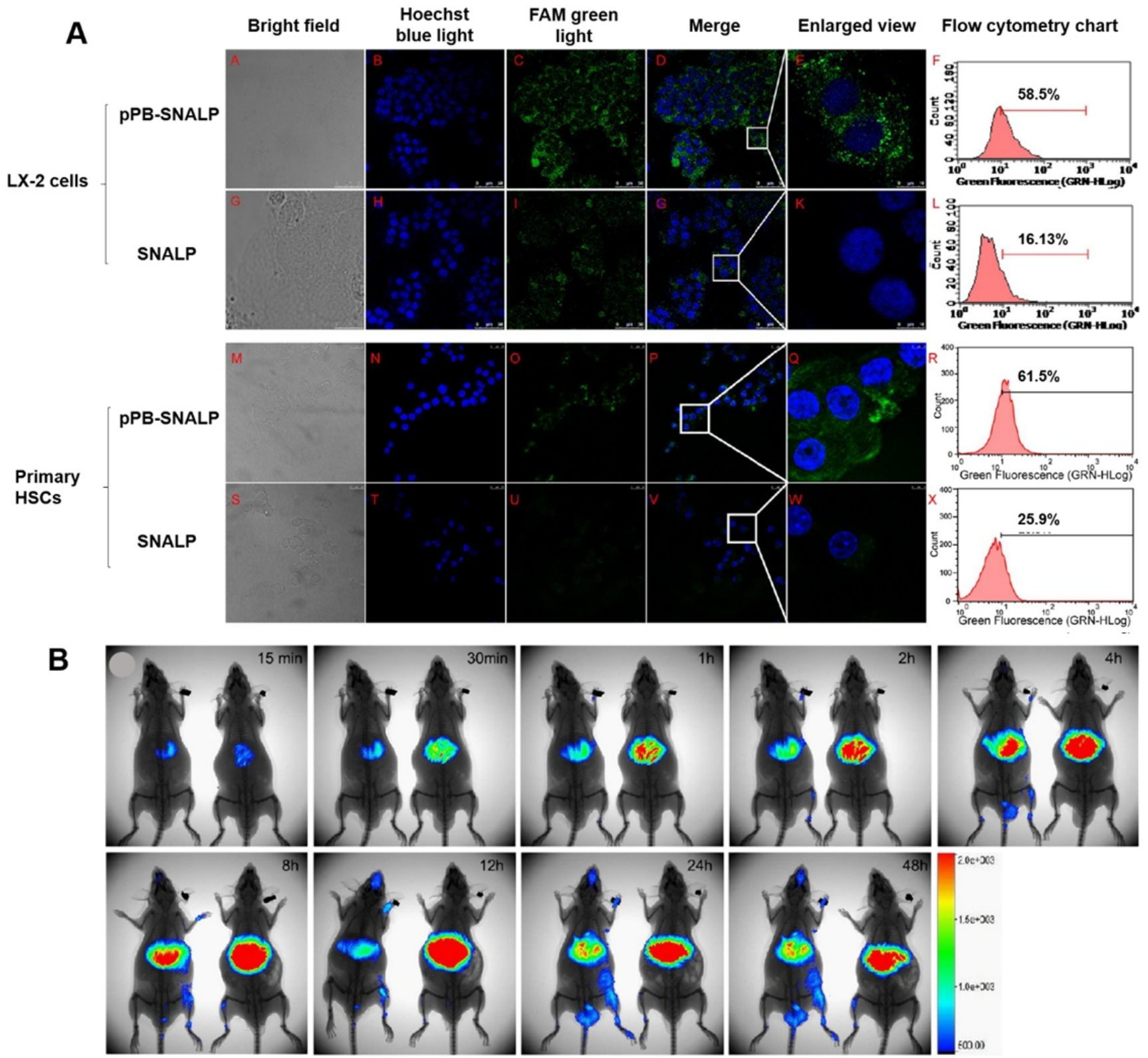

Fig. 6 Cellular uptake of pPB-SNALP and SNALP by LX-2 cells, and mouse primary HSC examined by confocal microscopy and flow cytometry (A). Biodistribution of DiR-labeled SNALP (left) and pPB-SNALP (right) in high gp46 mRNA expression Kunming mice at different time points in vivo following i.v. injection (B). Reprinted with permission from ref. 27. Copyright 2018, American Chemical Society.

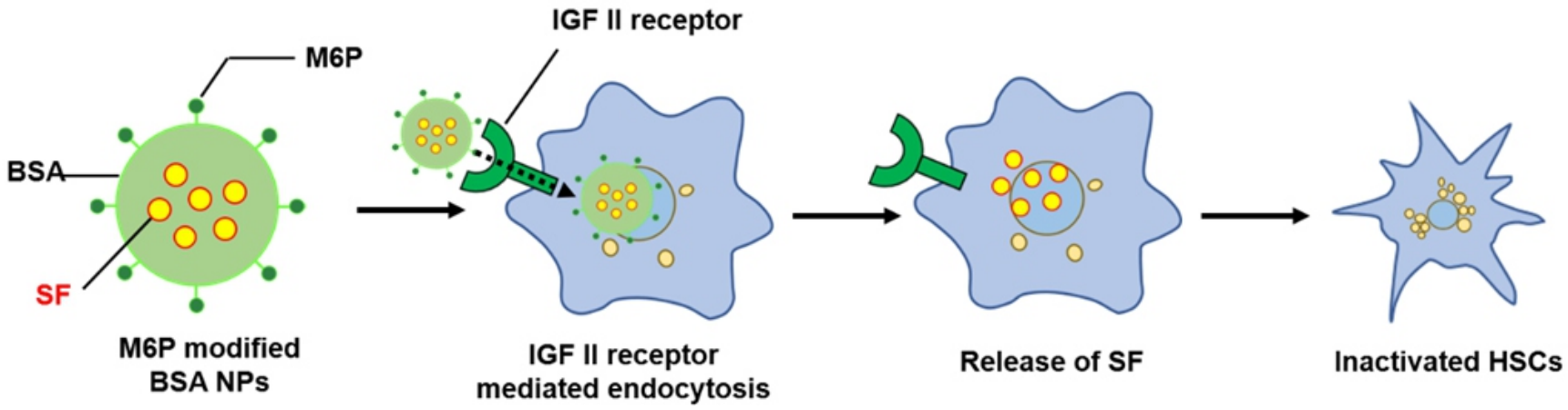

Fig. 7 The schematic illustration of ligand grafted nanoparticles for HSC targeting delivery: M6P-grafted nanoparticles. The drawings of hepatic stellate cells are adapted from ref. "S. L. Friedman, Proceedings of National Academy of Sciences of the United States, 2012, 109, 9230-9231". Permission is not needed as specified on the publisher's website. Copyright 2012, National Academy of Sciences. 
siRNA.

2.3 M6P-grafted nanoparticles

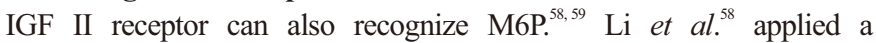
desolvation method to synthesize M6P modified neoglycoprotein-based nanoparticles with varying sizes of 100-200 nm and spherical structure (Fig. 7). Sodium ferulate (SF), a potential agent for the treatment of liver fibrosis, ${ }^{60}$ was pre-mixed with M6P-conjugated bovine serum albumin (BSA), and the desolvation procedure was initiated by adding 95\% ethanol into the mixture to form SF-loaded M6P-modified nanoparticles. Compared with free SF, when delivered in M6P-modified nanoparticles at a SF dose of $1.0 \mathrm{mg} / \mathrm{kg}$, SF accumulated significantly higher in the liver than other tissues in mice with BDL-induced liver fibrosis. Adrian et al. ${ }^{61}$ also prepared M6P-modified liposomes to test their targeting efficiency to HSC in vitro and in vivo. In this study, M6P-human serum albumin (M6P-HSA) conjugates were added into a lipid mixture to form liposomes with a particle size of $100 \mathrm{~nm}$. Uptake of M6P-modified liposomes by activated HSC was 4-fold higher than that of unmodified liposomes. Peroxisome proliferator-activated receptor $\gamma$ (PPAR $\gamma$ ), a member of nuclear hormone receptor superfamily, is highly expressed in quiescent HSC with diminished expression in activated HSC, ${ }^{62,63}$ and its agonist can prevent PDGF-induced HSC proliferation and migration which induces apoptosis of activated HSC. Patel et $a l^{64}$ developed M6P-HSA modified liposomes using a thin film hydration method to selectively deliver rosiglitazone (RGZ), a PPAR $\gamma$ agonist, to activated HSC. When compared with unmodified nanoparticles and free RGZ, M6P-HSA modified liposomes showed a marked increase in the hepatic uptake of RGZ by 2.61 folds and 4.93 folds, respectively, in mice with $\mathrm{CCl}_{4}$-induced liver fibrosis. Consequently, when RGZ was delivered to mice in M6P-HAS modified liposomes, liver fibrosis was markedly prevented with minimum side effects.

\subsection{CXCR4 antagonist-grafted nanoparticles}

The activation of stromal cell-derived factor 1 (SDF-1 $\alpha$ )/CXCR 4 axis is known to induce HSC activation and proliferation, leading to the secretion of VEGF, angiogenesis, progressive fibrogenesis, and abnormal angioarchitecture. ${ }^{36,65}$ Liu et al $^{66}$ constructed liposomes containing VEGF siRNA for the targeted delivery to HSC. AMD 3100 octahydrochloride hydrate, a CXCR4 antagonist, was incorporated into

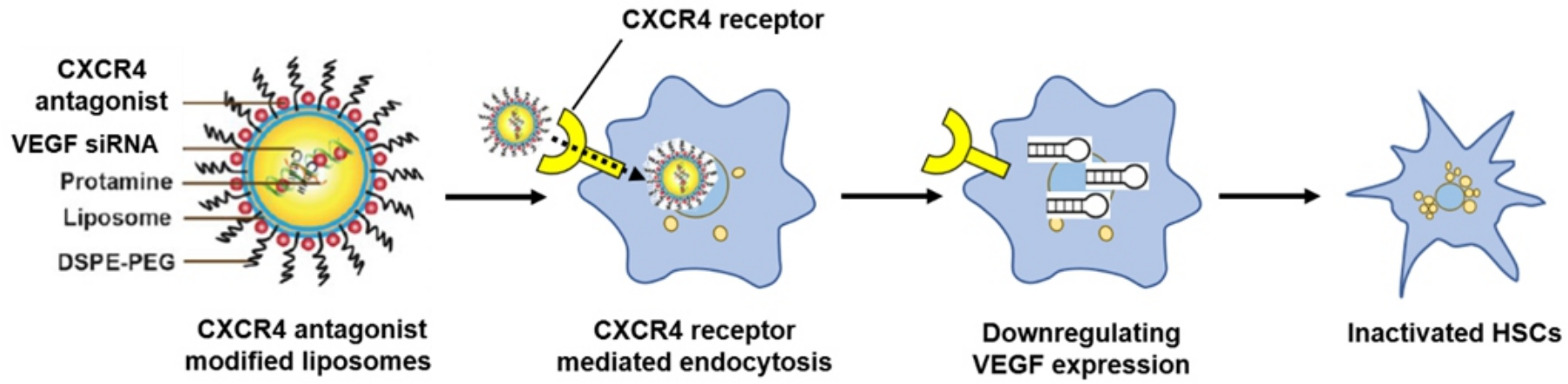

Fig. 8 The schematic illustration of ligand grafted nanoparticles for HSC targeting delivery: CXCR4 antagonist-grafted nanoparticles. The drawings of hepatic stellate cells are adapted from ref. "S. L. Friedman, Proceedings of National Academy of Sciences of the United States, 2012, 109, 9230-9231". Permission is not needed as specified on the publisher's website. Copyright 2012, National Academy of Sciences.

\section{DSPE-PEG : Peptide (molar ratio)}

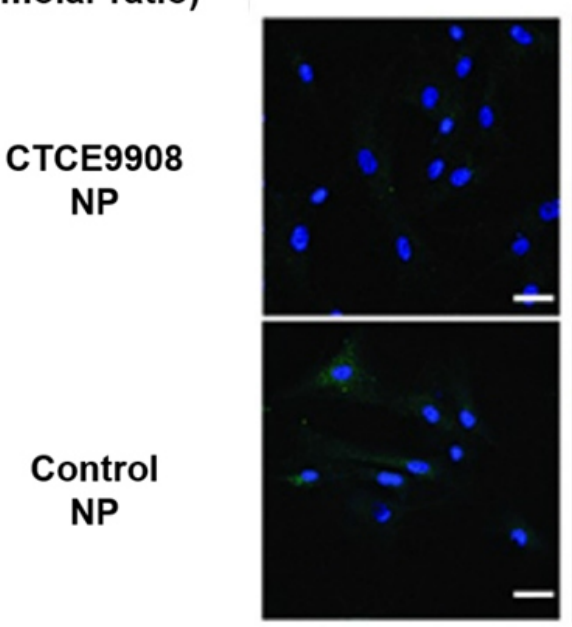

$5: 1$
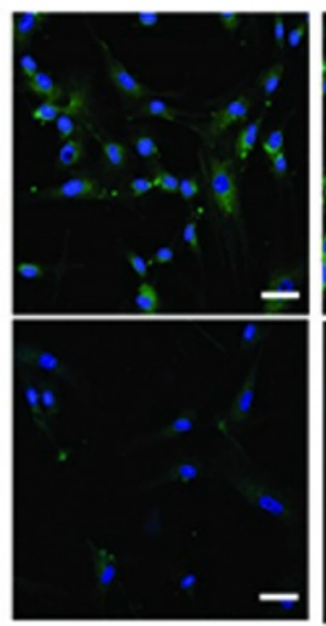

$5: 2.5$
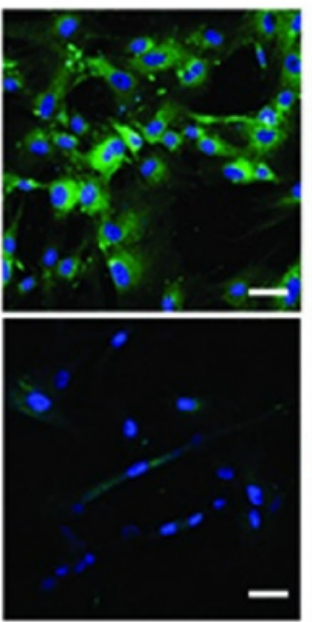

$5: 5$

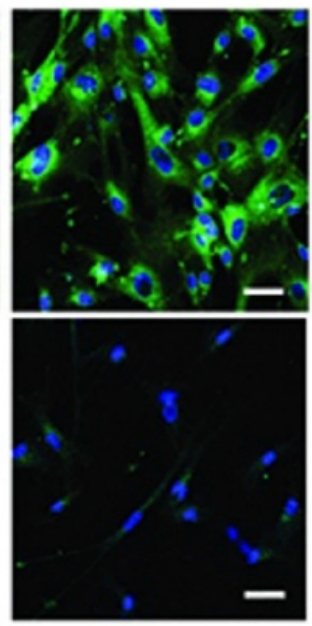

Fig. 9 HSC were treated with coumarin 6-loaded NPs modified with CTCE9908 peptides (CTCE9908-NPs) or scramble peptides (control-NPs) at various ratios of DSPE-PEG/peptides for $4 \mathrm{~h}($ scale bar $=50 \mu \mathrm{M})$. green, coumarin 6-loaded NPs; blue, DAPI. Reprinted from ref. 67, an open access article. Permission is not needed as specified on the publisher's website. Copyright 2018, Ivyspring International Publisher. 
the liposomes to suppress the progression of fibrosis by inhibiting the proliferation and activation of HSC. Specifically, a core complex was prepared by mixing protamine and VEGF siRNA together, which was further encapsulated into negatively charged liposomes followed by surface modification with AMD 3100 (Fig. 8). DSPE-PEG was also inserted into the lipid bilayer of the liposomes to extend their time in the circulation. When mice with $\mathrm{CCl}_{4}$-induced liver fibrosis were treated with the liposomes at a siRNA dose of $1.5 \mathrm{mg} / \mathrm{kg}$, the progression of liver fibrosis was significantly inhibited. In another study, Sung et al. ${ }^{67}$ conjugated a CXCR4 antagonist with PLGA nanoparticles and DSPEPEG were also grafted on the surface of the nanoparticles to stabilize the nanostructure. Uptake of the peptide-modified nanoparticles by activated HSC was significantly increased with increasing molar ratios of peptide to DSPE-PEG compared with control unmodified nanoparticles, as shown in Fig. 9. Both sorafenib and mitogen-activated protein kinase kinase (MEK) inhibitors were co-encapsulated into the PLGA nanoparticles to improve their therapeutic effect on liver fibrosis. Treatment with the CXCR4-targeted nanoparticles significantly suppressed the progression of liver fibrosis and the development of hepatocellular carcinoma as evidenced by significant decreases in liver nodules, tumor size, and desmoplasia in $\mathrm{CCl}_{4}$-induced mice.

\subsection{Hyaluronic acid (HA)-grafted nanoparticles}

CD44 is a main cell surface receptor of HA, which is upregulated in cancer cells and activated HSC. ${ }^{35}$ Therefore, grafting HA on nanoparticles may be useful for HSC-targeting delivery of anti-fibrotic agents. Recently, HA-modified nanoparticles containing curcumin with an average particle size of $60-70 \mathrm{~nm}$ were fabricated by Chen et al. ${ }^{68}$ as shown in Fig. 10. To increase loading efficiency by decreasing curcumin leakage from the nanoparticles, polyvinyl alcohol (PVA) was used as a stabilizing agent and HA was crosslinked on polylactide by adipic acid dihydrazide for selective uptake by HSC. After internalization into cells, curcumin induced apoptosis of activated HSC without affecting quiescent HSC. In addition, when curcumin was delivered in the nanoparticles, it ameliorated liver fibrosis to a similar degree to free curcumin at a dose of $20 \mathrm{mg} / \mathrm{kg}$, but with $\sim 30$-fold lower cytotoxicity, which was confirmed in mice with thioacetamide-induced liver fibrosis.

\section{Non-ligand nanoparticles for treating activated HSC through systemic delivery}

In addition to conjugating nanoparticles with HSC-targeting ligands, non-ligand nanoparticles may also be utilized to target activated HSC through systemic administration. Chang et $a l .^{69}$ prepared docetaxel (DTX)-loaded PEGylated carboxymethyl cellulose (CMC) nanoparticles with a particle size of $120 \mathrm{~nm}$ and DTX loading efficiency of $37 \%$. When administered intravenously, the nanoparticles were efficiently taken up by HSC and they exerted an anti-fibrotic effect in mice with $\mathrm{CCl}_{4}$-induced liver fibrosis. It is speculated that in the circulation the nanoparticles may bind to albumin and secreted protein acidic and rich in cysteine (SPARC) which are highly produced from activated HSC and other stromal cells in fibrotic and malignant tissues while avoiding non-specific uptake into normal cells. In addition, Safer et al. fabricated chitosan/tripolyphosphate nanoparticles using an ionic gelation method and evaluated their biological efficacy to treat liver fibrosis via systematic administration. When the nanoparticles containing green tea extract were intravenously administered to mice with $\mathrm{CCl}_{4}$-induced liver fibrosis, the anti-fibrotic effect of green tea extract when administered as part of nanoparticles was stronger than free green tea extract control. Compared with polymeric nanoparticles, lipid-based nanoparticles are known to reach the liver via systemic circulation due to their hydrophobic property. ${ }^{70,71}$ A lipid-based nanoparticulate delivery system was prepared by Calvente et $a l^{72}$ to encapsulate siRNA for procollagen $\alpha 1$ (I). After intravenous injection of the nanoparticles to mice with $\mathrm{CCl}_{4}$-induced liver fibrosis at a siRNA dose of $400 \mu \mathrm{g} / \mathrm{kg}$, liver fibrosis was reversed with decreases in the expression of procollagen $\alpha 1$ (I) by $90 \%$ and collagen deposition by 40 $60 \%$. In another study, an oil in water emulsion solvent evaporation technique was used to fabricate silybin-encapsulated polymeric nanoparticles. ${ }^{73}$ During the preparation, the organic phase containing silybin, poly- $\varepsilon$-caprolactone, and dichloromethane was added into polyvinyl alcohol, followed by sonication and evaporation of dichloromethane. In male Wistar rats, the nanoparticles sustained the release of silybin for up to 10 days and showed better pharmacokinetic properties than the free drug, including maximal concentration $\left(\mathrm{C}_{\max }\right)$, area under the curve (AUC), half time $\left(\mathrm{t}_{1 / 2}\right)$, and elimination rate constant $(\mathrm{Ke})$. Furthermore, the hepatoprotective activity of the silybinloaded nanoparticles was also superior than that of free drug in a $\mathrm{CCl}_{4}^{-}$ treated rat model.

In addition to organic nanoparticles, it has been shown that inorganic nanoparticulate delivery systems may be used for the treatment of liver fibrosis. He et $a l^{74}$ synthesized mesoporous silica nanoparticles with an uniform particle size of $400 \mathrm{~nm}$, high surface area of $750 \mathrm{~m}^{2} / \mathrm{g}$, and large pore volume of $0.7 \mathrm{~cm}^{3} / \mathrm{g}$ to encapsulate salvianolic acid $\mathrm{B}$ (SAB), a negatively charged drug that has been proved to inhibit hepatic fibrosis. ${ }^{75} \mathrm{SAB}$ was loaded within the

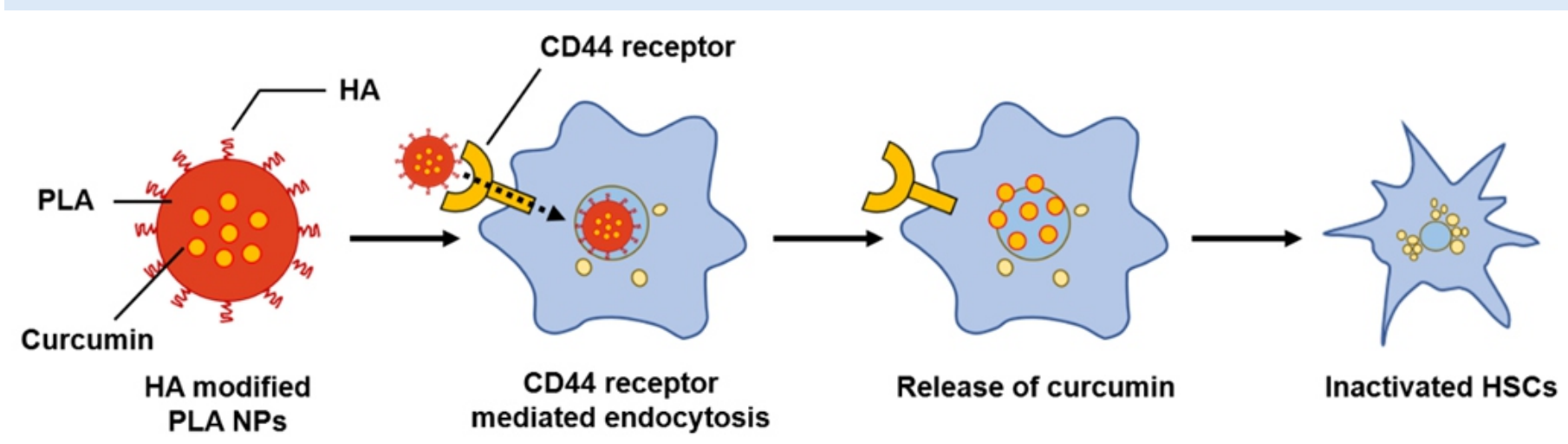

Fig. 10 The schematic illustration of ligand grafted nanoparticles for HSC targeting delivery: HA-grafted nanoparticles. The drawings of hepatic stellate cells are adapted from ref. "S. L. Friedman, Proceedings of National Academy of Sciences of the United States, 2012, 109, 9230-9231". Permission is not needed as specified on the publisher's website. Copyright 2012, National Academy of Sciences. 
nanoparticles through its binding to the mesoporous wall via hydrogen bonds and electrostatic interactions. The nanoparticles increased cellular uptake of SAB by LX-2 cells while reducing the total cellular level of reactive oxygen species compared with free $\mathrm{SAB}$ control. Although other inorganic nanoparticles, such as cerium oxide $\left(\mathrm{CeO}_{2}\right)$ nanoparticles ${ }^{76}$ and silver nanoparticles, ${ }^{77}$ have shown to exhibit antifibrogenic effects, a major concern on their use is a potential local and systemic toxicity. Exposure of the liver to $\mathrm{CeO}_{2}$ nanoparticles may lead to hydropic degeneration, hepatocyte enlargement and damage, and sinusoidal dilatation. ${ }^{78}$ Furthermore, despite the therapeutic effects of silver nanoparticles on liver diseases, ${ }^{79-81}$ their cytotoxicity in rat primary HSC has been reported. ${ }^{79}$ The silver nanoparticles induce the apoptosis of HSC in a size-dependent manner with smaller size particles being more pro-apoptotic possibly by disrupting mitochondrial membrane potential. Also, titanium dioxide $\left(\mathrm{TiO}_{2}\right)$ nanoparticles can cause liver injury. ${ }^{23}$ After oral administration of $\mathrm{TiO}_{2}$ at a dose of $150 \mathrm{mg} / \mathrm{kg} /$ day for 2 weeks to male Wistar albino mice, oxidative stress, fibrosis and angiogenesis in the liver were observed. In summary, although systemic administration of non-ligand nanoparticles has been demonstrated to be a potential strategy for the treatment of liver fibrosis, the ligandconjugated nanoparticles are more advantageous than non-ligand nanoparticles due to their high efficiency in drug delivery and low toxicity.

\section{Concluding remarks and future directions}

Therapies for liver fibrosis using HSC-targeting nanoparticulate delivery systems have emerged as a promising treatment. While nanoparticles engineered with various targeting ligands on their surface are a promising strategy for the treatment of liver fibrosis, the followings should be explored to improve the safety and therapeutic efficacy of HSC-targeting nanoparticles. First, cytotoxicity associated with nanomaterials should be carefully evaluated. Organic materials are likely better than inorganic materials as they have better biocompatibility and biodegradability with lower immunogenicity and toxicity compared to inorganic nanomaterials. Second, although targeting ligands may be conjugated to nanoparticles for selective delivery of anti-fibrotic drugs to HSC, the potential toxicity and adverse effects of the drugs are major concerns of their clinical applications. Therefore, the use of anti-fibrotic nutrients or siRNA of fibrogenic genes may be more desirable than drugs. Furthermore, when testing the biological efficacy of nanoparticle delivery systems in animal models, most of nanoparticles were administered by intravenous injection instead of oral administration. Oral delivery is widely recognized as a preferred route of drug administration because of minimal invasiveness, convenience and patient compliance in both short- and long-term treatment. ${ }^{82}$ Therefore, the development of HSC-targeting nanoparticles with good gastrointestinal stability, mucus permeability and transepithelial transport ability for oral administration should be explored to treat liver fibrosis. In addition, the safety and biological efficacy of HSC-targeting nanoparticles must be tested in humans to confirm findings from preclinical studies.

\section{References}

1. M. Shulman and Y. Nahmias, in Epithelial Cell Culture Protocols, Springer, 2012, pp. 287-302.

2. P. Ramachandran and J. Iredale, QJM: Int. J. Med., 2012, 105, 813-817.

3. R. Bataller and D. A. Brenner, J. Clin. Invest., 2005, 115, 209-218.

4. S. L. Friedman, J. Hepatol., 2003, 38, 38-53.

5. Z. Kmieć, in Cooperation of Liver Cells in Health and Disease, Springer,
2001 , pp. $51-59$

6. M. H. Ismail and M. Pinzani, Saudi J. Gastroenterol., 2009, 15, 72.

7. D. Povero, C. Busletta, E. Novo, L. V. di Bonzo, S. Cannito, C. Paternostro and M. Parola, Histol. Histopathol., 2010, 25, 1075-1091.

8. S. L. Friedman, Gastroenterology, 2008, 134, 1655-1669.

9. C. Yin, K. J. Evason, K. Asahina and D. Y. Stainier, J. Clin. Invest., 2013, 123, 1902-1910.

10. S. P. Surendran, R. G. Thomas, M. J. Moon and Y. Y. Jeong, Int. J. Nanomedicine, 2017, 12, 6997.

11. G. Svegliati-Baroni, Y. Inagaki, A. R. Rincon-Sanchez, C. Else, S. Saccomanno, A. Benedetti, F. Ramirez and M. Rojkind, Hepatology, 2005, 42, 343-352.

12. M. Moreno and R. Bataller, Clin. Liver Dis., 2008, 12, 825-852.

13. Y. A. Lee, M. C. Wallace and S. L. Friedman, Gut, 2015, 64, 830-841.

14. C. Wang, X. Song, Y. Li, F. Han, S. Gao, X. Wang, S. Xie and C. Lv, PLoS One, 2013, 8, e70725.

15. J. Zhou, D. W. Zhong, Q. W. Wang, X. Y. Miao and X. D. Xu, World J. Gastroenterol., 2010, 16, 3330.

16. S. M. Wilhelm, L. Adnane, P. Newell, A. Villanueva, J. M. Llovet and M. Lynch, Mol. Cancer Ther, 2008, 7, 3129-3140.

17. N. Kabir, H. Ali, M. Ateeq, M. F. Bertino, M. R. Shah and L. Franzel, RSC Adv., 2014, 4, 9012-9020.

18. K. Y. Yang, A. M. Y. Du Hyeong Hwang, D. W. Kim, Y. J. Shin, O. N. Bae, Y. I. Kim, J. O. Kim, C. S. Yong and H. G. Choi, Int. J. Nanomedicine, 2013, 8, 3333 .

19. F. Zhang, Z. Zhang, L. Chen, D. Kong, X. Zhang, C. Lu, Y. Lu and S. Zheng, J. Cell. Mol. Med., 2014, 18, 1392-1406.

20. Y. Yang, B. Kim, Y. K. Park, S. I. Koo and J. Y. Lee, Biochim. Biophys. Acta -Gen. Subj., 2015, 1850, 178-185.

21. Y. Yang, M. Bae, B. Kim, Y. K. Park, S. I. Koo and J. Y. Lee, J. Nutr. Biochem., 2016, 29, 21-26.

22. B. Kim, C. Farruggia, C. S. Ku, T. X. Pham, Y. Yang, M. Bae, C. J. Wegner, N. J. Farrell, E. Harness and Y.-K. Park, J. Nutr. Biochem., 2017, 43, 27-35.

23. S. A. Abdelazim, H. A. Darwish, S. A. Ali, M. Z. Rizk and M. O. Kadry, Cell. Physiol. Biochem., 2015, 35, 2402-2411.

24. J. Huang, J. Hu, L. Qiu and Z. Cai, Yao Xue Xue Bao, 2004, 39, 577-580.

25. A. M. A. Safer, N. A. Hanafy, D. J. Bharali, H. Cui and S. A. Mousa, J. Nanosci. Nanotechnol., 2015, 15, 6452-6459.

26. Z. Zhao, Y. Li, A. Jain, Z. Chen, H. Liu, W. Jin and K. Cheng, Nanomedicine:NBM, 2018, 14, 51-61.

27. Z. Jia, Y. Gong, Y. Pi, X. Liu, L. Gao, L. Kang, J. Wang, F. Yang, J. Tang and W. Lu, Mol. Pharm., 2017, 15, 53-62.

28. A. Tachaprutinun, T. Udomsup, C. Luadthong and S. Wanichwecharungruang, Int. J. Pharm., 2009, 374, 119-124.

29. F. Tamjidi, M. Shahedi, J. Varshosaz and A. Nasirpour, Innov. Food Sci. Emerg. Technol., 2014, 26, 366-374.

30. K. Tatiparti, S. Sau, S. Kashaw and A. Iyer, Nanomaterials, 2017, 7, 77.

31. H. Senoo, Med. Electron Microsc., 2004, 37, 3-15.

32. X. Zhou, F. R. Murphy, N. Gehdu, J. Zhang, J. P. Iredale and R. C. Benyon, J. Biol. Chem., 2004, 279, 23996-24006.

33. P. J. De Bleserc, P. Jannes, S. C. Van Buul Offers, C. M. Hoogerbrugge, C. F. Van Schravendijk, T. Niki, V. Rogiers, J. L. Van Den Brande, E. Wisse and A. Geerts, Hepatology, 1995, 21, 1429-1437.

34. N. Kinnman, C. Francoz, V. Barbu, D. Wendum, C. Rey, R. Hultcrantz, R. Poupon and C. Housset, Lab. Invest., 2003, 83, 163.

35. S. Kikuchi, C. T. Griffin, S. S. Wang and D. M. Bissell, J. Biol. Chem., 2005, 280, 15398-15404.

36. F. Hong, A. Tuyama, T. F. Lee, J. Loke, R. Agarwal, X. Cheng, A. Garg, M. I. Fiel, M. Schwartz and J. Walewski, Hepatology, 2009, 49, 2055-2067.

37. Y. S. Lee and W. I. Jeong, J. Gastroenterol. Hepatol., 2012, 27, 75-79.

38. N. Toriyabe, Y. Sakurai, A. Kato, S. Yamamoto, K. Tange, Y. Nakai, H. Akita and H. Harahsima, J. Pharm. Sci., 2017, 106, 2046-2052.

39. Y. Sato, K. Murase, J. Kato, M. Kobune, T. Sato, Y. Kawano, R. Takimoto, K. Takada, K. Miyanishi and T. Matsunaga, Nat. Biotechnol., 2008, 26, 431.

40. T. L. Pan, P. W. Wang, C. F. Hung, I. A. Aljuffali, Y. S. Dai and J. Y. Fang, Colloids Surf. B Biointerfaces, 2016, 141, 584-594.

41. D. C. Rockey, Clin. Liver Dis., 2008, 12, 939-962.

42. L. Giannitrapani, M. Soresi, M. L. Bondì, G. Montalto and M. Cervello, 
World J. Gastroenterol., 2014, 20, 7242.

43. K. Hayashi, T. Maruhashi, W. Sakamoto and T. Yogo, Adv. funct. mater, 2018, 28, 1706332

44. H. T. Duong, Z. Dong, L. Su, C. Boyer, J. George, T. P. Davis and J. Wang, Small, 2015, 11, 2291-2304.

45. Y. Iwakiri, Clin. Mol. Hepatol., 2015, 21, 319.

46. Y. Iwakiri and M. Y. Kim, Trends Pharmacol. Sci., 2015, 36, 524-536.

47. E. Langford, A. Brown, A. de Belder, R. Smith, J. Martin, R. Wainwright, M. Thomas, M. Radomski and S. Moncada, Lancet., 1994, 344, 1458-1460.

48. L. Li, T. Wu, J. Huang, K. Ma, L. Xu, H. Wang, X. Fan, R. Tao, G. Ai and Q. Ning, Parasitology, 2015, 142, 341-351.

49. W. C. Zhou, Q. B. Zhang and L. Qiao, World J. Gastroenterol., 2014, 20 , 7312.

50. A. Kolate, D. Baradia, S. Patil, I. Vhora, G. Kore and A. Misra, J. Control. Release, 2014, 192, 67-81.

51. J. Xuan, Y. Chen, L. Zhu, Y. Guo, L. Deng, Y. Zheng, Z. Wang, Z. Wang and M. Ao, Oncotarget, 2017, 8, 108676.

52. S. L. Du, H. Pan, W. Y. Lu, J. Wang, J. Wu and J. Y. Wang, J. Pharmacol. Exp. Ther., 2007, 322, 560-568.

53. X. W. Meng, B. R. Chi, L. G. Chen, L. L. Zhang, Y. Zhuang, H. Y. Huang and X. Sun, World J. Gastroenterol., 2005, 11, 3962.

54. F. Li, J. Y. Sun, J. Y. Wang, S. L. Du, W. Y. Lu, M. Liu, C. Xie and J. Y. Shi, J. Control. Release, 2008, 131, 77-82.

55. W. H. Kim, K. Matsumoto, K. Bessho and T. Nakamura, Am. J. Pathol., 2005, 166, 1017-1028.

56. Y. Matsuda, K. Matsumoto, T. Ichida and T. Nakamura, Int. J. Biochem., 1995, 118, 643-649.

57. R. S. Shukla, B. Qin, Y. J. Y. Wan and K. Cheng, Pharm. Res., 2011, 28, 3058-3068

58. F. Q. Li, H. Su, X. Chen, X. J. Qin, J. Y. Liu, Q. G. Zhu and J. H. Hu, J. Pharm. Pharmacol., 2009, 61, 1155-1161.

59. J. E. Adrian, J. A. Kamps, G. L. Scherphof, D. K. Meijer, C. Reker-Smit, P. Terpstra and K. Poelstra, Biochim. Biophys. Acta Biomembr, 2007, 1768, 1430-1439.

60. H. Wang, R. Peng, R. Wang and R. Kong, Yao Хие Xue Bao, 1997, 32, 511514.

61. J. E. Adrian, K. Poelstra, G. L. Scherphof, G. Molema, D. K. Meijer, C. Reker-Smit, H. W. Morselt and J. A. Kamps, J. Hepatol., 2006, 44, 560-567.

62. A. Galli, D. Crabb, D. Price, E. Ceni, R. Salzano, C. Surrenti and A. Casini, Hepatology, 2000, 31, 101-108.

63. E. M Zardi, L. Navarini, G. Sambataro, P. Piccinni, F. M Sambataro, C. Spina and A. Dobrina, Curr. Med. Chem., 2013, 20, 3370-3396.
64. G. Patel, G. Kher and A. Misra, J. Drug Target., 2012, 20, 155-165.

65. C. Corpechot, V. Barbu, D. Wendum, N. Kinnman, C. Rey, R. Poupon, C. Housset and O. Rosmorduc, Hepatology, 2002, 35, 1010-1021.

66. C. H. Liu, K. M. Chan, T. Chiang, J. Y. Liu, G. G. Chern, F. F. Hsu, Y. H. Wu, Y. C. Liu and Y. Chen, Mol. Pharm., 2016, 13, 2253-2262.

67. Y. C. Sung, Y. C. Liu, P. H. Chao, C. C. Chang, P. R. Jin, T. T. Lin, J. A. Lin, H. T. Cheng, J. Wang and C. P. Lai, Theranostics, 2018, 8, 894.

68. Y. N. Chen, S. L. Hsu, M. Y. Liao, Y. T. Liu, C. H. Lai, J. F. Chen, M. H. T. Nguyen, Y. H. Su, S. T. Chen and L. C. Wu, Int. J. Environ. Res. Public Health, 2016, 14, 11

69. C. C. Chang, Y. Yang, D. Y. Gao, H. T. Cheng, B. Hoang, P. H. Chao, L. H. Chen, J. Bteich, T. Chiang and J. Y. Liu, J. Drug Target., 2018, 26, 516-524.

70. L. Li, H. Wang, Z. Y. Ong, K. Xu, P. L. R. Ee, S. Zheng, J. L. Hedrick and Y.-Y. Yang, Nano Today, 2010, 5, 296-312.

71. A. Akinc, M. Goldberg, J. Qin, J. R. Dorkin, C. Gamba-Vitalo, M. Maier, K. N. Jayaprakash, M. Jayaraman, K. G. Rajeev and M. Manoharan, Mol. Ther, $2009,17,872-879$.

72. C. Jiménez Calvente, A. Sehgal, Y. Popov, Y. O. Kim, V. Zevallos, U. Sahin, M. Diken and D. Schuppan, Hepatology, 2015, 62, 1285-1297.

73. C. R. Bonepally, S. J. Gandey, K. Bommineni, K. M. Gottumukkala and J. Aukunuru, Trop. J. Pharm. Res., 2013, 12, 1-6.

74. Q. He, J. Zhang, F. Chen, L. Guo, Z. Zhu and J. Shi, Biomaterials, 2010, 31, 7785-7796.

75. P. Liu, Y. Y. Hu, C. Liu, D. Y. Zhu, H. M. Xue, Z. Q. Xu, L. M. Xu, C. H. Liu, H. T. Gu and Z. Q. Zhang, World J. Gastroenterol., 2002, 8, 679.

76. D. Oró, T. Yudina, G. Fernández-Varo, E. Casals, V. Reichenbach, G. Casals, B. G. de la Presa, S. Sandalinas, S. Carvajal and V. Puntes, J. Hepatol., 2016, 64, 691-698.

77. X. Sun, Z. Wang, S. Zhai, Y. Cheng, J. Liu and B. Liu, Mol. Med. Rep., 2013, 8, 1365-1372.

78. S. K. Nalabotu, M. B. Kolli, W. E. Triest, J. Y. Ma, N. D. Manne, A. Katta, H. S. Addagarla, K. M. Rice and E. R. Blough, Int. J. Nanomedicine, 2011, 6, 2327.

79. M. J. Piao, K. A. Kang, I. K. Lee, H. S. Kim, S. Kim, J. Y. Choi, J. Choi and J. W. Hyun, Toxicol. Lett., 2011, 201, 92-100.

80. L. Lu, R. Sun, R. Chen, C. K. Hui, C. M. Ho, J. M. Luk, G. Lau and C. M. Che, Antivir. Ther, 2008, 13, 253.

81. J. E. Choi, S. Kim, J. H. Ahn, P. Youn, J. S. Kang, K. Park, J. Yi and D.-Y. Ryu, Aquat. Toxicol., 2010, 100, 151-159.

82. A. Sosnik and R. Augustine, Adv. Drug Deliv. Rev., 2016, 103, 105-120.

Publisher's Note Engineered Science Publisher remains neutral with regard to jurisdictional claims in published maps and institutional affiliations. 